\title{
ESPANHOL COMO LÍNGUA ESTRANGEIRA EM TEMPOS DE PANDEMIA: ATIVIDADES SÍNCRONAS QUE APENAS O ENSINO REMOTO PROPORCIONA
}

\author{
Español como Lengua Extranjera en Tiempos de Pandemia: actividades \\ síncronas que solo las clases virtuales proporcionan
}

Fernanda PIZZA

Universidade Federal do Paraná

rch.pizza@gmail.com https://orcid.org/0000-0003-4730-7854

Tuanny EUGENIO

Universidade Federal do Paraná tuannyeugenio@gmail.com https://orcid.org/0000-0002-9423-3985

\begin{abstract}
RESUMO: Em 2020, a pandemia do Covid-19 atingiu todo o planeta e modificou completamente as formas de interação social. Diversos setores foram comprometidos, assim como a Educação, e todos precisaram se adaptar. Portanto, no momento atual, a reinvenção e a (re)aprendizagem são essenciais para que se possa construir novas alternativas de ensino, e no FIVU-UFPR (Formação em Idiomas para Vida Universitária - Universidade Federal do Paraná) não foi diferente. Pensando nisso, o projeto abriu espaço para estudantes do curso de Letras da UFPR desenvolverem seus estágios obrigatórios com a criação de um curso montado integralmente no formato online para estudantes da pós-graduação em Educação. Porém, pensando em tornar as aulas mais atrativas e dinâmicas, metodologias, atividades e interações tiveram que ser adaptadas. Sendo assim, além do aprimoramento como professores, através desse estágio obrigatório, houve a oportunidade de aprender mais sobre a área tecnológica. Por integrarmos a equipe de professores em formação nesse projeto, apresentamos, neste artigo, alguns exemplos de atividades que foram pensadas para essa nova modalidade de ensino e que tiveram um resultado positivo no processo de ensino/aprendizagem. PALAVRAS-CHAVE: ensino remoto; ensino de espanhol; atividades síncronas.
\end{abstract}

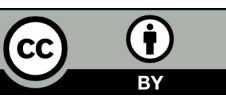


RESUMEN: En 2020, la pandemia del Covid-19 alcanzó todo el mundo y cambió completamente las formas de interacción social. Varios sectores fueron perjudicados, así como la Educación, y todos tuvieron que adaptarse. Por lo tanto, en el momento actual, la reinvención y el reaprendizaje son fundamentales para que se pueda construir nuevas posibilidades de enseñanza, y en FIVU - UFPR (Formação em Idiomas para Vida Universitária - Universidade Federal do Paraná) no fue diferente. Pensando en eso, el proyecto abrió espacio para que estudiantes de la carrera de Letras de la UFPR pudieran desarrollar sus prácticas obligatorias con la creación de un taller hecho totalmente online para alumnos del Postgrado en Educación. Pero, pensando en dejar las clases más interesantes y dinámicas, metodologías y actividades tuvieron que ser adaptadas. Así siendo, además del aprimoramento como profesores, a través de esta práctica obligatoria, hubo la oportunidad de aprender más sobre el área tecnológica. Por hacer parte del grupo de profesores en formación en este proyecto, presentaremos en este artículo algunos ejemplos de actividades que fueron pensadas para esa nueva modalidad de enseñanza y que tuvieron un resultado positivo en el proceso de enseñanza/aprendizaje. PALABRAS-CLAVE: enseñanza remota; enseñanza de español; actividades síncronas.

\section{ENSINO REMOTO: DESAFIOS DE UM "NOVO MUNDO"}

Com o surgimento da pandemia do coronavírus em 2020, todos os setores da sociedade sofreram grandes modificações, e os processos de ensino e aprendizagem também tiveram que se adaptar a esse momento atípico. A reinvenção e a reaprendizagem do profissional de educação são essenciais para que possamos construir novas alternativas de ensino, e no projeto de extensão Formação em Idiomas para a Vida Universitária ${ }^{1}$ (FIVU) não foi diferente. Pensando nisso, o projeto abriu espaço para os estudantes de Letras que cursavam a disciplina de Prática de Docência de Línguas Estrangeiras Modernas Neolatinas poderem desenvolver seus estágios obrigatórios dentro de um curso montado integralmente no formato virtual do ensino remoto para estudantes da pós-graduação em Educação, também da Universidade Federal do Paraná (UFPR). Importante ressaltar aqui que, diferentemente de outros módulos do projeto, esse módulo online de língua espanhola não teve um professor regente na turma. Cada dupla de praticantes, assumia a regência das turmas por uma semana e, assim, fomos alternando.

\footnotetext{
${ }^{1}$ Com o tempo, o projeto Formação em Línguas para Fins Acadêmicos passou a se chamar Formação em Idiomas para a Vida Universitária (FIVU).
} 
Além do aprimoramento como professores, nós e os outros alunos da disciplina que atuamos como praticantes no projeto, tivemos a oportunidade de aprender mais sobre a área tecnológica que a cada dia se faz mais necessária dentro da profissão, mas que até esse momento tinha um desenvolvimento um pouco mais lento. Silva, Shitsuka e Moraes (2013) abordam justamente a marginalização do ensino EaD e apontam para um aprimoramento de estratégias metodológicas em todo tipo de ambiente de aprendizagem, e não para a extinção das plataformas virtuais.

$\mathrm{O}$ atual contexto mundial nos mostrou que o uso de tecnologias por parte de docentes e discentes em todos os níveis da Educação se tornou indispensável para a continuidade das atividades educacionais. Assim, integrando a equipe de professores no referido projeto, falaremos sobre os desafios e aprendizados proporcionados por essa nova modalidade, que, para nós, é uma nova forma de ensino.

Levando em consideração autores como Bourdieu (1999), que fala sobre trazer a realidade do aluno para a sala de aula, e Bakhtin (1997), que discorre sobre os gêneros do discurso e a interpretação de textos focada nos gêneros, abordaremos as práticas trabalhadas em aula com os alunos e mostraremos propostas de atividades que só tiveram seu desenvolvimento possibilitado porque as aulas foram feitas em uma plataforma de webconferência (Microsoft Teams).

As propostas aqui apresentadas fizeram com que os alunos desse módulo online do FIVU desenvolvessem uma relação com o meio em que eles estão inseridos para o ensino de língua espanhola, trabalhando nas aulas a interpretação de textos de gênero acadêmico, assim, focando no principal objetivo do curso, o exame de suficiência na língua espanhola. Apesar de o curso ter como objetivo a preparação dos alunos para o Exame de Suficiência em Língua Estrangeira da UFPR, e deste exigir apenas uma habilidade, a da leitura - obviamente nessa habilidade está incorporada a interpretação de texto - , durante o curso do FIVU foram trabalhadas as quatro habilidades linguísticas: compreensão e produção escrita e compreensão e produção oral.

\section{EM BUSCA DE ATIVIDADES ADAPTADAS AO ENSINO REMOTO}

Começar a atuar no âmbito do ensino remoto em um processo emergencial no qual a pandemia nos colocou foi muito mais desafiador do que atuar na sala de aula física. O primeiro desafio foi que docentes e discentes tiveram que, simultaneamente, aprender e se adaptar. E para nós, praticantes de docência atuando no projeto, o aprendizado foi mais intenso e feito em um espaço de tempo curto, uma vez que nossos conhecimentos e metodologias de ensino/aprendizagem se voltavam para o ambiente físico de ensino, a Revista X, v. 16, n. 4, p. 1079-1100, 2021. 
sala de aula. Logo, tivemos que adaptar e transformar nossos métodos para o ambiente virtual, além de buscar novas ferramentas e maneiras de desenvolver os materiais didáticos e de conduzir as aulas num ambiente que era novo e desafiador para os alunos e ainda mais para os professores. Isso porque tínhamos que guiar os alunos para o melhor aproveitamento das plataformas usadas - Google Classroom para as atividades assíncronas e Microsoft Teams para as aulas síncronas².

Outro desafio está relacionado ao fato de o ensino remoto ser uma modalidade recente na área da educação no Brasil. Muito se assemelha ao $\mathrm{EaD}$, mas, ainda assim, possui algumas características particulares. Seguindo a definição de Veloso e Walesko (2020)

\begin{abstract}
Muitas das ações que foram incentivadas pelas universidades brasileiras dizem respeito ao Ensino Remoto Emergencial (ERE), que, de certo modo, assemelha-se à Educação a Distância $(\mathrm{EaD})$, dado que também é educação mediada por tecnologia. No entanto, o ERE não prevê o apoio de tutores e carga horária distribuída em atividades síncronas e assíncronas, além de não possuir uma legislação específica. (VELOSO; WALESKO, 2020, p. 36-37)
\end{abstract}

Para fins didáticos, pensamos o ensino remoto baseadas nas referências de Ensino a Distância (EaD), já que ambas as definições se assemelham e que as experiências com o ERE são recentes. Nesse sentido, uma grande preocupação foram as questões metodológicas e de qualidade do ensino.

É bastante comum ouvir de pessoas que nunca tiveram uma experiência de aulas em EaD certo receio de que a qualidade seja inferior ao sistema convencional. Porém, deve-se levar em conta, nesse caso, que muitos dos sistemas convencionais também possuem, em grande parte, problemas dos mais diversos, sendo necessário, portanto, avaliar na verdade, não a modalidade, mas as estratégias de ensino/aprendizagem

\footnotetext{
${ }^{2}$ Estamos considerando as definições de síncrona e assíncrona que constam no Novo Dicionário da Língua Portuguesa (1986) e no Dicionário Online de Português Dicio, respectivamente:

sincrônico - 1. Que ocorre ao mesmo tempo. 2. Relativo aos fatos concomitantes ou contemporâneos. 3. Relativo a, ou em que há sincronia.

assíncrono - 1. Que não ocorre ou não se efetiva ao mesmo tempo. 2. Que não acontece juntamente com outra coisa. 3. Que não mantém uma sincronia, com intervalos regulares, por não ser controlado por um sistema temporizador.

Conforme definição, usaremos síncrono quando nos referimos às atividades feitas pelos discentes no horário das aulas previamente combinado com professores, realizadas sincronicamente. E assíncrono quando nos referimos às atividades desenvolvidas pelos estudantes em horários distintos.
} 
de qualquer curso, independente da modalidade. (SILVA; SHITSUKA; MORAES, 2013, p. 13).

Como bem colocam Silva, Shitsuka e Moraes, o que define a qualidade do ensino, seja ele na modalidade que for, são as estratégias utilizadas. Por isso, analisaremos neste capítulo alguns exemplos de atividades utilizadas para tornar as aulas mais dinâmicas e atrativas. Mas, primeiro, é importante explicar como essas aulas foram pensadas.

As aulas de Espanhol como língua estrangeira, ministradas na modalidade de ensino remoto, tinham duração de aproximadamente uma hora e 40 minutos. Esse tempo parece longo em uma aula presencial de língua estrangeira, principalmente porque não tínhamos intervalo como geralmente acontece em aulas mais longas na modalidade presencial. No entanto, o ritmo das aulas na plataforma virtual é um pouco mais lento. Nas primeiras aulas ministradas foi possível sentir essa diferença, pois não foi viável trabalhar todo o material desenvolvido, já que a base temporal que tínhamos era das aulas presenciais. Porém, nas aulas seguintes conseguimos entender a diferença desse tempo de resposta necessário na modalidade síncrona a distância, preparando um material mais adequado temporalmente para esse tipo de aula. Vários fatores fazem com que o tempo seja administrado de forma diferente nessa modalidade. Dentre eles, destacamos:

\section{Acesso à internet:}

Nem todos os alunos têm acesso a uma conexão de internet de qualidade. A incidência de atrasos é maior, porque a conexão do aluno à sala virtual varia, consequentemente cabe aos professores lidar com os imprevistos, como, por exemplo, atrasar o início das atividades até que todos estejam conectados. Durante as aulas houve momentos em que as conexões falharam e precisamos repetir falas ou esperar por alguns minutos a resposta dos alunos.

\section{Tempo de resposta:}

A espera no tempo de resposta dos alunos é maior quando falamos de aulas em formato remoto, mesmo que sejam atividades síncronas. Como não estamos perto fisicamente para incentivar a participação dos alunos, apontando, lançando um olhar a eles ou simplesmente pedindo que se manifestem, que falem, que participem, eles demoram um pouco mais para participar. Entretanto, geralmente os alunos participaram 
bastante da interação, mas nesse caso também se deve levar em conta as possíveis falhas de conexões da internet, entre outros problemas técnicos.

\section{Participação em aula:}

Um fato inesperado e positivo para nós foi a participação dos alunos nas aulas. Pelo fato de estarem "protegidos" por estarem atrás de um computador e não cara a cara com professores e colegas, acreditamos que os alunos em sua maioria se sentiram mais seguros e menos intimidados em participar das aulas e arriscar falar em uma língua estrangeira, na qual estavam apenas iniciando seus estudos. Esse fato nos surpreendeu, especialmente nas tentativas incansáveis dos alunos de usar a língua estrangeira - o espanhol - ao participar de discussões promovidas pelos professores.

A compreensão de texto, para o Teste de Suficiência em Espanhol como Língua Estrangeira da UFPR, era o principal objetivo a ser desenvolvido no curso. Todavia, ademais de considerá-lo, foi acordado - pelos professores e coordenadora do curso ${ }^{3}$ que seriam trabalhadas e desenvolvidas durante todo o curso, e de forma integrada, em consonância com o ensino da língua sob uma perspectiva comunicativa sociodiscursiva, todas as habilidades linguísticas para o ensino de uma língua estrangeira, formando alunos que seriam capazes de fazer uso dessas quatro habilidades na língua espanhola (compreensão e produção oral, compreensão e produção escrita) em nível básico ${ }^{4}$, a fim de torná-los proficientes nessa língua para realizar algumas tarefas simples, tipicamente desenvolvidas por acadêmicos. Discutindo proficiência em língua estrangeira, Giraldello e Tedesco (2016) afirmam que

[...] a palavra proficiência, apesar de confusões terminológicas e conceituais, pode ser concebida como a capacidade de uso da competência linguístico-comunicativa, está norteada e articulada pelos aspectos textuais, sociolinguísticos, gramaticais e estratégicos. Assim, para um aluno ser proficiente, nesse processo, estão envolvidas habilidades linguísticas. (GIRALDELLO; TEDESCO, 2016, p. 27-28).

Para desenvolver as habilidades linguísticas na língua alvo, foram empregadas diversas estratégias e atividades, algumas delas que só puderam ser realizadas devido ao fato de que as aulas foram ministradas dentro do ensino remoto. Mais adiante

\footnotetext{
${ }^{3}$ Professora doutora Fernanda Veloso. Professora da Prática de Docência em Língua Estrangeira Moderna II: Espanhol/Francês/Italiano. Orientadora do módulo de Espanhol Básico 1, no ensino remoto do FIVU.

${ }^{4}$ Curso de Espanhol - Módulo 1/2020 (CE - M1/2020).

Revista X, v. 16, n. 4, p. 1079-1100, 2021. 
apresentaremos e detalharemos a aplicação de cinco dessas atividades, usadas em nossas aulas. No entanto, primeiro comentaremos e discorreremos através de um aspecto geral sobre como as atividades colaboraram para a progressão das quatro habilidades linguísticas no decorrer do curso.

Trabalhar através da perspectiva de Bakhtin e preparar as aulas levando em consideração os gêneros do discurso facilitava a interação nas aulas, pois colocava os alunos como protagonistas do processo de ensino/aprendizagem. Segundo Bakhtin, os gêneros do discurso são descritos como "tipos relativamente estáveis de enunciados" (1997, p. 279). Para o autor, o termo enunciado é definido como:

Todas as esferas da atividade humana, por mais variadas que sejam, estão sempre relacionadas com a utilização da língua. Não é de surpreender que o caráter e os modos dessa utilização sejam tão variados como as próprias esferas da atividade humana, o que não contradiz a unidade nacional de uma língua. A utilização da língua efetua-se em forma de enunciados (orais e escritos), concretos e únicos, que emanam dos integrantes duma ou doutra esfera da atividade humana. $\mathrm{O}$ enunciado reflete as condições específicas e as finalidades de cada uma dessas esferas, não só por seu conteúdo (temático) e por seu estilo verbal, ou seja, pela seleção operada nos recursos da língua - recursos lexicais, fraseológicos e gramaticais —, mas também, e sobretudo, por sua construção composicional. (BAKHTIN, 1997, p. 279).

Importante ressaltar que estamos considerando materiais autênticos aqueles textos extraídos do "mundo real". De acordo com Santos (2014, p. 18), textos autênticos se constituem de textos diversos, produzidos não com o propósito de ensinar, mas são textos que circulam em uma comunidade ou na internet com objetivos e leitores diversos. A inclusão de textos autênticos faz com que os estudantes tenham contato com a língua em contexto natural em que ela ocorre. Aliado a isso, o texto autêntico direciona o ensino não só para a língua, mas também para o uso da linguagem na interação social. Além disso, buscar documentos ${ }^{5}$ e temas que dialoguem com o cotidiano dos alunos também contribui para baixar o "filtro afetivo" citado por Krashen e analisado por Chacón e Josephy (2011) no texto "El efecto del filtro afectivo en el aprendizaje de una segunda

\footnotetext{
${ }^{5}$ Estamos considerando como documentos os materiais autênticos selecionados por nós para compor os materiais que utilizamos nas aulas (sejam textos, imagens, vídeos, áudios etc.).

${ }^{6}$ De acordo com a teoria de Krashen, "filtro afetivo" são barreiras que podem ser criadas pelos alunos no processo de ensino/aprendizagem. Se esse filtro se mantém baixo, os alunos têm um aproveitamento melhor no processo. Por isso a importância de o professor tentar atravessar essas barreiras e manter o filtro afetivo baixo.
} 
lengua". A vantagem em buscar diminuir o filtro afetivo está em criar ou aumentar uma conexão dos alunos com a língua que está sendo aprendida, tendo a intenção de transformar o ambiente da sala de aula em um lugar mais acolhedor. A busca, de nossa parte, por usar materiais autênticos que fizessem parte do conhecimento prévio dos alunos, facilitou com que eles se sentissem à vontade para falar em aula pelo interesse que eles já tinham pelos assuntos abordados nas aulas; uma estratégia que ajudou a aumentar sua participação oral durante as aulas.

Outro ponto que merece destaque foi a decisão de não os interromper durante suas falas, mesmo que cometessem equívocos ou usassem algumas palavras em português, o que lhes deu mais liberdade para falar. As correções eram feitas através do chat da reunião no aplicativo Microsoft Teams, ou, após a fala dos alunos, nós, professores, usávamos a mesma palavra pronunciando-a da maneira correta. Também foi uma tentativa, na nossa opinião acertada, de trabalhar na diminuição do "filtro afetivo".

Consideramos a importância de levar para as aulas materiais que façam uma conexão entre língua e cultura, concordando com Janzen (2008) que, em seu texto intitulado "Concepções de cultura e o ensino de línguas estrangeiras modernas", explica que a concepção tradicional de cultura:

[...] implica a busca do apagamento das diferenças sócio-culturais, de modo a propiciar uma homogeneização do grupo. A homogeneidade interna possibilita a delimitação externa, uma vez que o que é estranho é externo ao grupo. Um dos movimentos de unificação interna e delimitação externa é o de negação dos valores e crenças do outro, do estranho, reforçando uma perspectiva etnocêntrica (comum à visão tradicional de cultura). (JANZEN, 2008, p. 64).

Por isso, entendemos a importância de levar para as aulas elementos culturais diversificados dos povos hispano-falantes e atrelar as discussões culturais ao ensino da língua estrangeira. Para além de romper estereótipos pré-estabelecidos, aulas com tais temáticas também promovem uma reflexão histórica e profunda sobre questões linguísticas. Afinal, a língua de um povo sempre evolui conectada com a sua cultura.

Levando em conta todas essas questões e as diferenças entre o ensino presencial e remoto, demos preferências a alguns tipos de atividades que percebemos serem favorecidas pelo formato virtual. Atividades pensadas para serem desenvolvidas no ambiente virtual se tornam mais atrativas quando a aula toda acontece virtualmente. Por exemplo, se chamamos um convidado hispano nativo e esse convidado só pode estar presente de forma virtual, é diferente quando todos estão presentes de forma 
virtual também. A atenção depositada na atividade é maior porque, inclusive, a pessoa está sozinha no ambiente presencial (ou em um ambiente silencioso). Se pensamos no ambiente de uma sala de aula presencial, essa dinâmica não aconteceria da mesma forma. Muitos imprevistos podem acontecer e isso se torna mais atrativo e dispersa a concentração do aluno na atividade sendo desenvolvida virtualmente. Se estamos juntos no ambiente virtual e separados no ambiente físico, até mesmo a conversa, a atenção ao que acontece no virtual parece ser maior, o que gera vantagens para determinados tipos de atividades.

Para as escolhas das atividades a serem propostas, nos baseamos em definições que consideram atividades como "tarefa" dentro de um propósito sociocomunicativo, o que difere da abordagem tradicional e abre um leque maior de possibilidades, inclusive para o trabalho com materiais autênticos, ou seja, a língua em uso dentro de um contexto real, e que termina com uma proposta de interação que dialoga com o documento, a ser desenvolvida pelos alunos para reforçar o aprendizado. Segundo Scaramucci:

Tarefa é um termo usado em Linguística Aplicada para se referir a uma atividade de ensino ou de avaliação diferente daquela usada nas abordagens tradicionais. Ela tem um propósito comunicativo, especificando para a linguagem usos que se assemelham àqueles que se têm na vida real. Ela permite a apresentação de conteúdos "autênticos", ou seja, extraídos de jornais, revistas e livros, não necessariamente elaborados para o ensino de línguas, e sempre dentro de um contexto maior de comunicação, [...]. (SCARAMUCCI, 2001, p. 80).

Ainda tratando sobre as definições de tarefa, Santos (2014) aponta que uma tarefa deve "direcionar as práticas didáticas a objetivos socioculturais e discursivos" para "não limitar o ensino à organização cumulativa de conteúdos linguísticos". E como as aulas foram pensadas para que fossem uma boa experiência dentro do ensino remoto, já que as metodologias utilizadas nas aulas presenciais estavam sendo adaptadas, era importante não sobrecarregar as tarefas/atividades de conteúdos linguísticos.

Pensando nisso, desenvolvemos diversas atividades síncronas com os alunos para tornar as aulas mais dinâmicas e atrativas. A seguir, listamos alguns exemplos:

\section{Quizz sobre falsos cognatos}

Para essa atividade, usamos o site Educaplay, em que montamos um questionário (Anexo 1) sobre falsos cognatos entre português e espanhol. Como usamos a plataforma Teams para dar as aulas, usamos o chat do aplicativo para enviar o link para os alunos 
e também o aplicativo Whatsapp, para que eles pudessem ter acesso ao site. Essa atividade foi desenvolvida aproximadamente após 40 a 50 minutos de aula, depois de eles executarem exercícios gramaticais, mas antes da explicação desse conteúdo.

$\mathrm{O}$ objetivo da atividade era que os alunos tivessem um primeiro contato com essas palavras, porém de maneira mais "leve", fazendo com que eles não tivessem obrigação de saber o significado delas, mas que descobrissem seus significados através da dedução e dos próprios equívocos, pois com essas palavras o que parece óbvio não é o correto. Criamos uma maneira para eles entrassem em contato com esse conteúdo de um jeito mais divertido do que apenas memorizar palavras em uma tabela, mas que pudessem aprender através de um jogo, em que de alguma maneira usariam essas palavras pensariam e indagariam sobre elas, brincando, sugerindo e se surpreendendo com o significado verdadeiro de cada palavra usada.

O interessante dessa atividade não foi apenas a participação dos alunos durante o jogo, mas como o questionário fez com que eles se interessassem pelas palavras mais intensamente do que se eles estivessem apenas lendo tabelas. Depois da realização dessa atividade os alunos participaram ativamente expondo quais palavras pareceram mais estranhas para eles, quais eles esperavam que tivessem um dado significado e era outro totalmente distinto e quais eles já conheciam. Além disso, alguns alunos que já viajaram para países onde a língua nativa é o espanhol e nós, professoras, demos exemplos através de histórias pessoais e divertidas sobre o uso de algumas dessas palavras, o que também ajuda no processo de compreensão de como usá-las e também na sua internalização.

Essa atividade estava baseada principalmente na compreensão escrita, mas através da atuação por parte dos alunos na discussão posterior à realização, também houve a prática da produção oral e, consequentemente, da compreensão oral.

\section{Podcast Antiprincesas}

Com essa atividade, tivemos a possibilidade de escutar com os alunos, de uma forma síncrona, uma breve história narrada na língua meta ${ }^{7}$ em formato de podcast. Escutamos de forma conjunta o capítulo "Origen de la liga de las Antiprincesas" do podcast Antiprincesas. Dessa forma, os alunos puderam praticar a compreensão oral e a atividade de escutar um episódio de podcast se tornou mais interessante do que se tivesse sido feita presencialmente, pois, como já mencionamos anteriormente, quando todos

\footnotetext{
${ }^{7}$ Estamos considerando como "língua meta" a língua espanhola. Ou seja, a língua que os alunos estão buscando aprender ao longo das aulas.
} 
estão em um ambiente virtual e sozinhos com o computador no espaço físico, o virtual se torna mais envolvente, pois, no espaço físico individual as chances de distrações ocorrerem ao redor do aluno parecem diminuir consideravelmente comparado com o espaço físico conjunto.

Além de ter sido uma atividade focada no desenvolvimento de habilidades linguísticas, colocou os alunos em contato com aspectos culturais do mundo hispano e também possibilitou que apresentássemos mais uma variante da língua espanhola, já que a produção do podcast em questão é argentina. De acordo com Janzen (2008, p. 75) "deve ser preservada a pluralidade cultural em associação com a tradição, a fim de proteger o homem do crescente processo de estranhamento". Ou seja, quanto mais se entra em contato com uma cultura diferente, menos essa cultura será considerada "estranha" e mais fácil será aceitar e entender as diferenças culturais com naturalidade. Por isso, nossa preocupação em trazer elementos culturais para serem apresentados e debatidos em classe. Em conformidade com o discurso de Janzen (2008), esse processo de aprendizagem de uma língua não deve ser desvinculado da realidade. E isso inclui o trabalho com elementos culturais dos povos que, nesse caso, tenham o espanhol como língua materna e/ou língua oficial.

Essa é uma atividade que pode ser desenvolvida em aulas presenciais, porém sabemos que os resultados no formato presencial e virtual são diferentes. E, nesse caso, o fato de estarmos trabalhando com aulas no ensino remoto foi uma vantagem pelo fato de os alunos, ao menos em nosso curso, estarem mais focados no que acontece virtualmente do que estariam se fosse uma aula presencial.

Como optamos por trabalhar com materiais autênticos, o podcast foi escutado diretamente na plataforma em que foi disponibilizado originalmente, Spotify (Anexo 2 - Podcast Antiprincesas), através do compartilhamento da tela e som no computador da professora, podendo, assim, ser trabalhado também o local onde foi disponibilizado o episódio do podcast. As professoras trabalharam com pré-leitura, leitura e pós-leitura do documento, o que contribuiu para tornar o contato com o documento mais real porque não foi didatizado, recortado ou extraído do ambiente onde foi postado.

Os resultados que colhemos foram muito positivos. A proposta da atividade era escutar o texto em forma de áudio e em seguida fazer um resumo colaborativo do texto. Percebemos os resultados através da motivação, foco e empenho dos alunos em construir esse resumo na língua meta. Um segundo objetivo da atividade, dessa vez implícito, era analisar se os conhecimentos sobre língua espanhola compartilhados até o momento 
haviam sido compreendidos pelos alunos, o que com a produção e desenvolvimento dessa atividade, parece ter sido alcançado.

Com o desenvolvimento do resumo oral, os alunos mostraram que estavam com suas habilidades de compreensão e produção oral dentro do esperado para esse momento, chegando na metade do módulo, nível básico. Além de demonstrarem sua evolução dos conhecimentos nos estudos de espanhol desde o início do curso até o momento. Como a atividade foi feita de forma síncrona, professoras e alunos puderam debater e construir o resumo em conjunto. Dessa forma, todos se ajudaram a compreender e a organizar o resumo. Ou seja, o foco não estava em nós, enquanto professoras; não estávamos na posição de detentoras do conhecimento. Esse conhecimento foi produzido de forma conjunta e o foco estava nos alunos e em suas produções, porém de uma forma sutil, sem inibir a participação de ninguém, pois, em grande parte dos momentos de ensino/ aprendizagem buscávamos propiciar um ambiente descontraído, e a interação, para os alunos, se assemelhava a uma conversa.

\section{Padlet: "La pared de los recuerdos"}

A descoberta dessa plataforma e todas as possibilidades de atividades síncronas que ela abre foram bem importantes e aconteceram em boa hora para a produção dos materiais para as aulas. O Padlet é uma plataforma que permite interação e construção síncronas de documentos colaborativos.

Para a penúltima aula, preparamos uma revisão, ou "retrospectiva", de tudo que foi trabalhado ao longo do curso. Pensando em fazer com que esse conhecimento partisse dos alunos e que fosse trabalhado de uma forma dinâmica e atrativa, demos início à aula propondo a construção de uma linha do tempo intitulada "La pared de los recuerdos" (Anexo 3) na plataforma Padlet.

Como a aplicação permite várias possibilidades de design, criamos um layout que simulava uma parede e iniciamos a linha do tempo que foi sendo preenchida pelos alunos com os conhecimentos gramaticais, temáticos ou culturais, que ficaram na memória deles depois das aulas.

Um dos objetivos pedagógicos dessa atividade era fazer com que os alunos visualizassem que o aprendizado de uma língua não está somente ligado às regras gramaticais, mas também à cultura dos povos que têm essa língua como língua materna. Um outro objetivo foi fazê-los perceber que as aulas estavam conectadas e que eles trilharam um grande caminho até chegar àquele momento quase de encerramento do curso. 
Segundo Janzen (2008), diversas vozes deveriam estar representadas nesse processo de ensino/aprendizagem. O autor aponta para a "pluridiscursividade" no ensino. "A partir de uma mudança de paradigma, as aulas de língua estrangeira deveriam problematizar os mais diversos temas da cultura-alvo." (JANZEN, 2008, p. 72). Tendo essa perspectiva em mente, buscamos diversificar as vozes nos materiais didáticos trazendo documentos autênticos de países diferentes e que traziam aspectos culturais diferentes, incluindo aspectos linguísticos de diferentes lugares do mundo hispano.

Outro objetivo dessa atividade era fazer uma conexão com a atividade seguinte do material preparado, sistematização do uso do "voseo". Como já havíamos trabalhado aspectos culturais e linguísticos da variante argentina da língua espanhola (atividade sobre o podcast das Antiprincesas), que tem como característica marcante o "voseo", usamos essa retrospectiva para conectar com uma tirinha da personagem Mafalda, utilizada na sequência, para contextualizar o uso do "voseo" e, em seguida, explicar e sistematizar gramaticalmente esse fenômeno latino-americano da língua espanhola.

\section{Google Forms como atividade simulativa}

Essa atividade foi a última a ser desenvolvida de maneira síncrona no curso, sendo realizada na última aula. Diferente das outras atividades, ela trouxe aos alunos um pouco de tensão, pois vinha acompanhada da palavra "simulado", visto que a ideia de fazer uma prova geralmente amedronta a maioria dos alunos. Mesmo sem ter o valor em nota, esse foi o momento em que de alguma forma o aluno ou a aluna e seu desenvolvimento no curso foi avaliado, que se pôde comprovar os resultados e conhecimentos obtidos durante todo o curso.

Foi decidido que os alunos responderiam cinco questões retiradas de provas anteriores de suficiência em espanhol como língua estrangeira da UFPR, e que para isso teriam entre 40 e 45 minutos, sendo a atividade mais longa que os alunos fizeram sozinhos durante as aulas. Intitulamos a atividade de "Simulación del Examen de Suficiencia en Lengua Española" e ele aconteceu na plataforma Google Forms. Nela, os alunos tinham disponível primeiro o texto para leitura e interpretação, que servia para responder as questões selecionadas. Logo em seguida, tinham as cinco questões, sendo todas de múltipla escolha, com cinco opções de resposta cada uma (Anexo 4). A maioria dos alunos usou todo o tempo disponível para terminar o simulado, e quase todos acertaram mais de três questões.

Tivemos receio que os alunos, ao ficarem tanto tempo executando uma atividade sozinhos, sem participação de colegas e professores, desistissem, saindo da Revista X, v. 16, n. 4, p. 1079-1100, 2021. 
aula antes de terminar. Para nossa surpresa, o que mais impressionou nessa atividade foi a discussão feita após o simulado, na qual os alunos tiveram uma participação em massa e extremamente aprofundada, utilizando a língua meta na maior parte do tempo e demonstrando um grande envolvimento com as questões e o texto - que, mais uma vez, propositalmente trazia conteúdos da área de interesse e de estudo dos alunos. Nela, os próprios alunos encontraram as soluções para as dúvidas dos colegas, que haviam surgido durante a leitura do texto e reflexão ao responder as questões enquanto faziam o simulado.

Uma das vantagens de usar o conhecimento de mundo dos alunos é que nesse caso específico usamos suas áreas de estudos e pesquisas (dentro da área de educação), sobre as quais eles se sentem mais livres e mais seguros para falar sobre o assunto. Tudo contribuiu para que os alunos usassem a língua meta nas discussões e ainda tiveram a oportunidade de entrar em contato com léxicos - específicos e gerais - que serão úteis nas suas áreas de atuação.

\section{Encontros síncronos com nativos}

Pensando no enriquecimento cultural e na motivação que os encontros com hispano falantes iriam proporcionar aos alunos do curso para aprender o espanhol, decidimos possibilitar a eles a oportunidade de escutar na língua meta uma pequena palestra cultural e temática sobre o país do convidado e praticar a língua estrangeira fora do contexto de sala de aula, interagindo diretamente com nativos. Kraviski e Bergmman (2006) evidenciam a dificuldade do contato com falantes nativos ao estudar uma língua estrangeira, e como os intercâmbios concebidos nesses encontros interculturais podem facilitar o progresso dos estudos da língua meta, incentivando o aluno a conhecer diversos países, culturas e pessoas, e assim aprimorar ainda mais a língua estudada. Elas ainda afirmam que "O ensino da cultura faz com que o aluno desenvolva as estratégias necessárias para atuar socialmente na cultura da língua-alvo" (KRAVISKI; BERGMMAN, 2006, p. 85). Os encontros com nativos hispanos, ocorreram todas as sextas desde o dia 5 de junho até o dia 24 de julho de 2020, das 9 h30 às 11h10, sendo que, no último encontro esse horário se estendeu até às $12 \mathrm{~h}$ pelo interesse demonstrado pelos participantes e pelos convidados nas discussões.

Esses encontros eram temáticos. Ou seja, os convidados hispanofalantes possuíam conhecimento na temática, além de interesse pessoal, de forma que pudessem desenvolver e elaborar a apresentação. Por exemplo, um médico falando sobre os sistemas de saúde em El Salvador e no Brasil, um músico falando sobre o rock argentino, um professor falando sobre o ensino de espanhol pelo mundo e assim sucessivamente. 
Nessas aulas, deixamos acordado, antes mesmo do início do curso, que a presença seria facultativa para os alunos. Infelizmente, nem todos os inscritos no curso tinham as manhãs de sexta-feira livres para os encontros culturais e o objetivo era alcançar o maior número de pessoas possível, incluindo a comunidade externa à universidade, para que esses eventos fossem mais atrativos para todos, com mais interação. Por esse motivo, iniciamos um processo de divulgação semanal de cada evento. Foram criados cartazes (Anexo 5) e todos os envolvidos no projeto ajudavam a divulgar o evento pelas redes sociais. Assim, com a divulgação, era disponibilizado o link de acesso para que outras pessoas também pudessem participar. Como resultado, alcançamos uma média de 15 a 20 pessoas a cada encontro e tendo em mente o aproveitamento tanto dos convidados como dos participantes, era um bom número.

No último desses encontros, pensando em fazer algo marcante para o encerramento do curso, convidamos cinco nativos hispanos para falar sobre os movimentos sociais em seus respectivos países - Argentina, Colômbia, Chile, País Basco (Espanha) e Peru. Seguindo a lógica dos encontros anteriores, foram convidadas pessoas que já tinham um envolvimento prévio com movimentos sociais. O intuito de colocar essas cinco pessoas juntas era para fazer uma comparação de como esse tema se desenvolvia nesses diferentes países, assim como colocar os alunos em contato com variantes de diferentes países para que pudessem colocar em prática seus aprendizados na língua espanhola desenvolvidos ao longo do curso.

Para que ficasse organizado e tivéssemos um certo controle do tempo, ficou estabelecido que cada convidado teria 15 minutos para fazer uma apresentação introdutória sobre seu país e os movimentos sociais da região sobre a qual a pessoa iria falar. Depois disso, seria aberta uma rodada de perguntas a fim de promover a interação entre todos os participantes. Como já pontuado, esse encontro durou quase uma hora a mais que o previsto porque os participantes estavam bem interessados e o diálogo entre todos aconteceu de forma natural.

Vários objetivos contribuíram para a criação dessa atividade. A princípio, seria mais um dia para que os professores tivessem a oportunidade de praticar a docência, pensando e desenvolvendo os objetivos de aprendizagem que seriam trabalhados em cada encontro. Além disso, também se tornou um espaço para que os discentes tivessem contato com hispano-falantes nativos. Os alunos e as pessoas da comunidade externa à universidade, que puderam participar também, conseguiram ter contato com muitos elementos linguísticos e culturais do espanhol. 
Além de contribuir para a aprendizagem da língua espanhola, a grande maioria dos convidados levou algum(ns) tipo(s) de documento(s) para compartilhar e ilustrar suas falas, tais como apresentações gráficas, vídeos e imagens. Houve trocas de conhecimentos que aconteceram com a interação que esses eventos geraram, bem como o crescimento nos conhecimentos interculturais compartilhados entre todos.

Essas foram as atividades mais interessantes e enriquecedoras desenvolvidas durante o curso. Afirmamos isso porque nesses encontros interculturais os alunos tinham a oportunidade de escutar e conversar com falantes nativos da língua espanhola, convidados pelos professores, que eram de diversos países que têm o espanhol como língua oficial. Segundo as professoras Kraviski e Bergmann, no texto "Interculturalidade e motivação na aprendizagem de línguas estrangeiras":

[...] quanto mais motivado o aluno está para aprender uma língua estrangeira, mais procurará conhecer e aproximar-se da realidade da comunidade de falantes; por outro lado, quanto mais próximo e consciente das diferenças e semelhanças culturais com a outra comunidade, mais motivado se sentirá para continuar seu intento de aprendê-la. [...] Os alunos, intrinsecamente motivados, aprendem a língua estrangeira com metodologias e métodos de caráter geral, que abordam aspectos culturais e sociais das comunidades em que a língua é falada. (KRAVISKI; BERGMANN, 2006, p. 78-79).

Através dessa interação entre o falante nativo convidado e os alunos do curso, ocorria a percepção e o reconhecimento de diferenças culturais e linguísticas, trocas, que faziam com que os alunos ficassem mais instigados e interessados em aprender, desenvolver e praticar seu conhecimento na língua espanhola.

\section{LIÇÕES APRENDIDAS COM A EXPERIÊNCIA NO AMBIENTE VIRTUAL}

O ensino remoto é capaz de promover atividades distintas e motivadoras, levando em conta o curto período de preparação que houve para o desenvolvimento delas e que o ensino presencial não é capaz de oferecê-las da mesma forma, pois a tecnologia é essencial nesse modelo de ensino. O que não é possível na realidade da maioria das escolas do ensino público do Brasil porque existe uma grande dificuldade em utilizar o ambiente virtual nas aulas presenciais, pois os recursos e conhecimentos tecnológicos (por parte dos docentes) muitas vezes é escasso. Sendo assim, não teríamos acesso a essas oportunidades se não fosse a necessidade de nos reinventar e repensar nas formas de ensino nesse momento atípico que estamos vivenciando globalmente. 
O aprendizado da língua espanhola, apesar de ter acontecido de maneira bastante distinta de como ocorre presencialmente, se desenvolveu bem e ao final sentimos que os alunos conseguiram melhorar suas habilidades de compreensão e produção oral, de leitura e escrita. Na fala percebemos a evolução durante o curso, principalmente nas últimas aulas, em que se evidenciaram as diferenças. Na compreensão oral percebemos como eles entendiam cada vez melhor os hispanofalantes nas aulas culturais das sextas-feiras. $\mathrm{Na}$ leitura, isso ocorreu através do simulado que fizeram na última aula, pois a maior parte dos alunos obteve um aproveitamento superior a 50\%. Na escrita, observamos, pela execução de tarefas assíncronas, como conseguiram ampliar o vocabulário e os conhecimentos na língua espanhola em comparação com as primeiras tarefas entregues.

Desde o princípio, tínhamos muita vontade de inovar e pensar dinâmicas que fizessem as aulas funcionarem, mas existiam fatores que ainda estavam fora do nosso alcance, como a participação dos alunos. Não tínhamos como prever como seria a resposta deles porque esse também era um "território" novo para nós. E ao contrário do que esperávamos, a participação dos alunos foi ativa. Isso nos faz concluir que no ensino remoto também se pode estabelecer uma boa comunicação e relação professoraluno e aluno-professor através do ambiente virtual. A experiência com o ensino remoto que o projeto FIVU nos proporcionou foi muito positiva e nos fez perceber que, independentemente do ambiente em que as aulas estão sendo ministradas, o mais importante é a escolha e adaptação das metodologias e ferramentas adequadas.

\section{REFERÊNCIAS}

BAKHTIN, M. M. Estética da criação verbal. 4. ed. São Paulo: Martins Fontes, 1997. (Biblioteca Universal).

BERGMANN, Juliana; KRAVISKI, Elys Regina. Interculturalidade e motivação na aprendizagem de línguas estrangeiras. Revista Intersaberes, v. 1 n. 1, p. 78-86, jan./jun. 2006.

CHACÓN, Ginnet Pizarro; JOSEPHY, Daniel. El efecto del filtro afectivo en el aprendizaje de una segunda lengua. Letras, Heredia, v. 48, p. 209-225, 2011.

GIRALDELLO, Ademir Paulo; TEDESCO, Anderson Luiz. (Re)pensando o ensinoaprendizagem de línguas estrangeiras. Entretextos, Londrina, v. 16, n. 1, p. 25-42, jan./ jun. 2016. 
INFOPÉDIA Capital Cultural. Porto: Porto Editora, 2003-2020. Disponível em: https:// www.infopedia.pt/\$capital-cultural. Acesso em: 15 dez. 2018.

JANZEN, Henrique E. Concepções de cultura e o ensino de Línguas estrangeiras modernas. In: SCHMIDT, Maria Auxiliadora; GARCIA, Tania Maria F. Braga; HORN, Geraldo Balduíno (org.). Diálogos e perspectivas de investigação. Ijuí: UNIJUÍ, 2008.

SANTOS, Jovania Maria P. dos. Proposta de critérios para elaboração de unidades temáticas e de enunciados de tarefas em contexto de ensino de PLE no CELINUFPR. 2014.

SCARAMUCCI, Matilde Virginia R. O projeto CELPE-Bras no âmbito do Mercosul: contribuições para uma definição de proficiência comunicativa. In: ALMEIDA FILHO, J. C. P. de (org.). Português para estrangeiros: interface com o espanhol. 2. ed. Campinas: Pontes, 2001.

SILVA, Priscilla C. D.; SHITSUKA, Ricardo; MORAIS, Gustavo. Estratégias de ensino/ aprendizagem em ambientes virtuais: estudo Comparativo do ensino de língua estrangeira no sistema EaD e presencial. Revista Brasileira de Aprendizagem Aberta e a Distância, v. 12, 2013.

VELOSO, Fernanda; WALESKO, Angela M. H. Estágio supervisionado remoto de línguas estrangeiras em tempos de pandemia: experiências e percepções na UFPR. Rev. Nova Paideia - Revista Interdisciplinar em Educação e Pesquisa. Brasília, v. 2, p. 3557, 2020.

\section{ANEXOS}

Anexo 1: Quizz falsos cognatos.

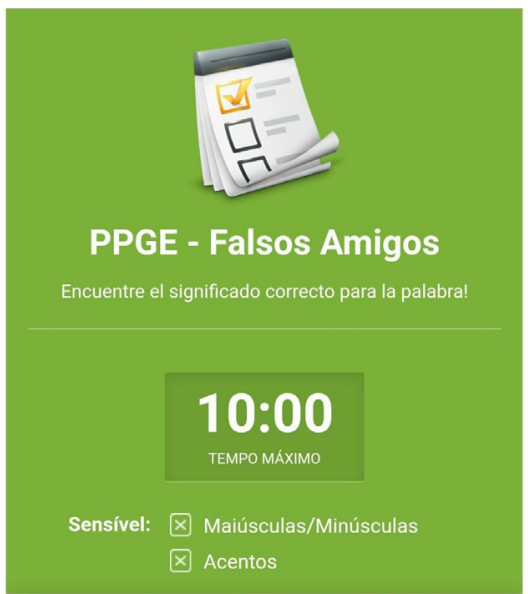


Anexo 2: Podcast Antiprincesas.

\section{8: La Liga Antiprincesas Presentación}

Antiprincesas Podcast

5 JUL. 2017 • QUEDAN 5 MIN

\section{REPRODUCIR}

$\alpha_{0}^{\circ}$

(1)

Nos embarcamos en una nueva aventura, la de contar historias de mujeres reales, pero esta vez que luchan todas juntas por las causas justas. ¿Quienes son? La liga de AntiPrincesas!

Agradecemos a Luci Arlequín por su canción "Guerreras".

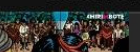

\section{9: Liga de Antiprincesas, El Origen}

(d) TUANNY-PC

Anexo 3: Padlet "La pared de los recuerdos".

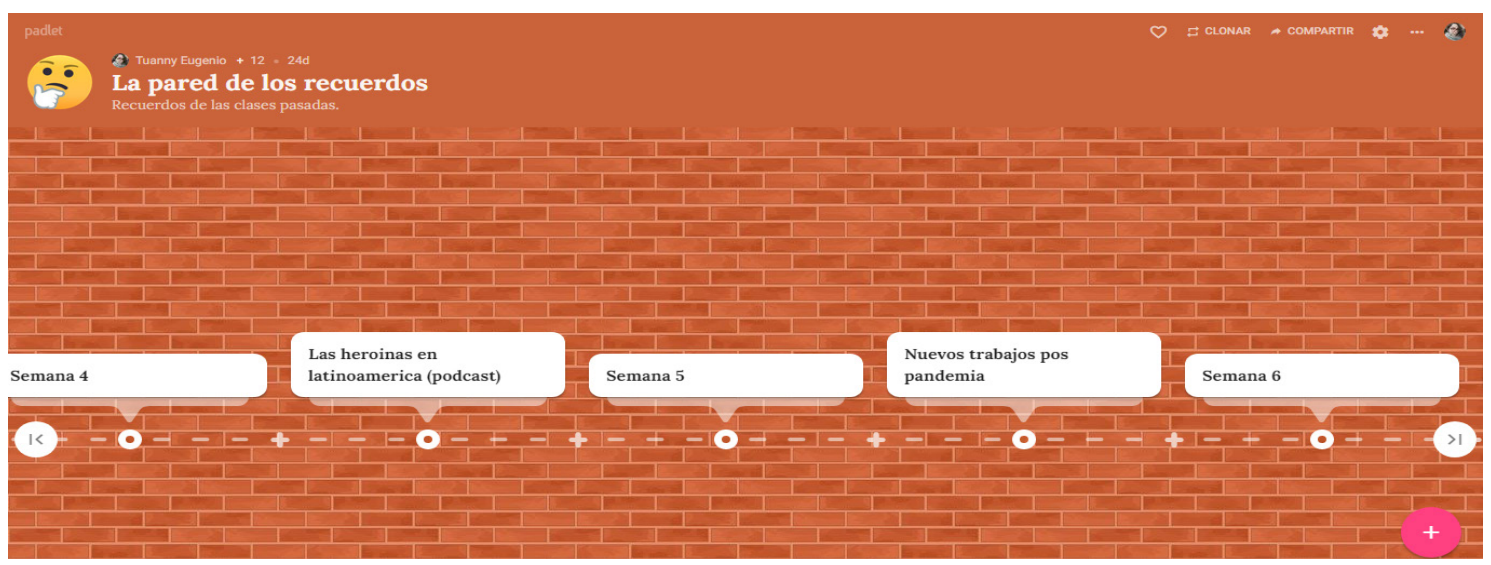


Anexo 4: Simulado no Google Forms.

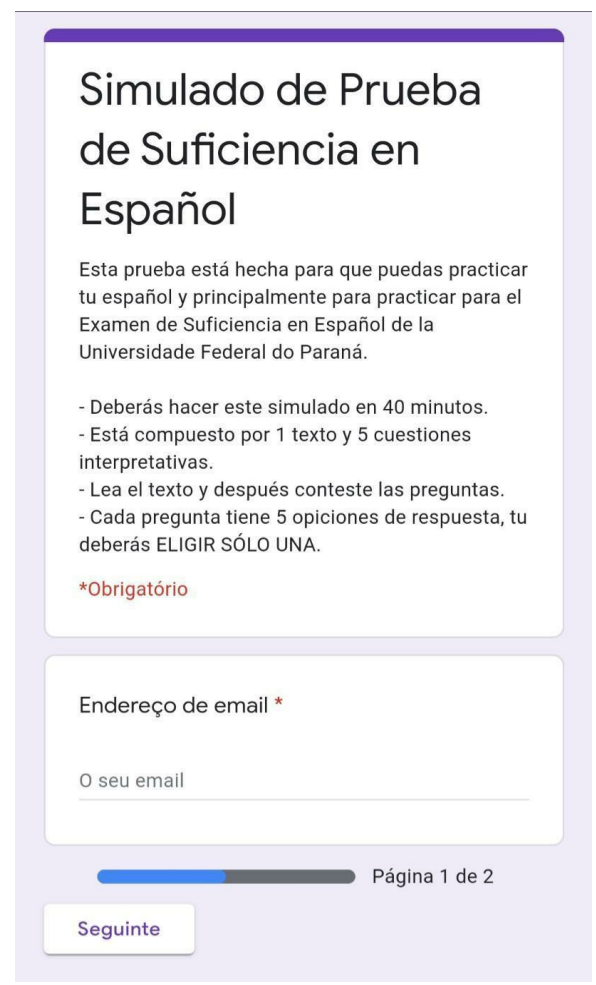

Anexo 5: Exemplos de cartazes das atividades culturais.
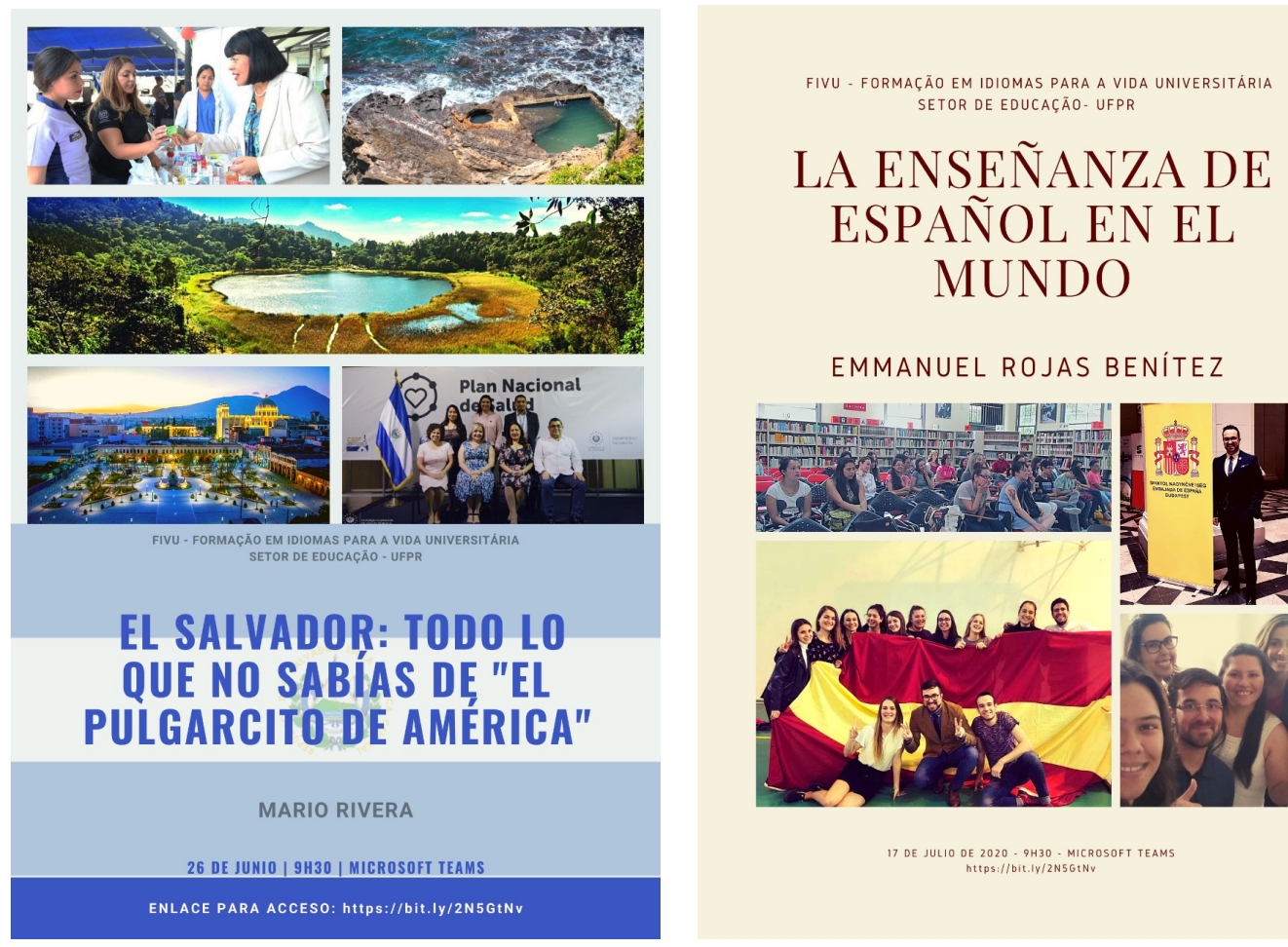
ESPAÑOL EN EL MUNDO

EMMANUEL ROJAS BENITEZ

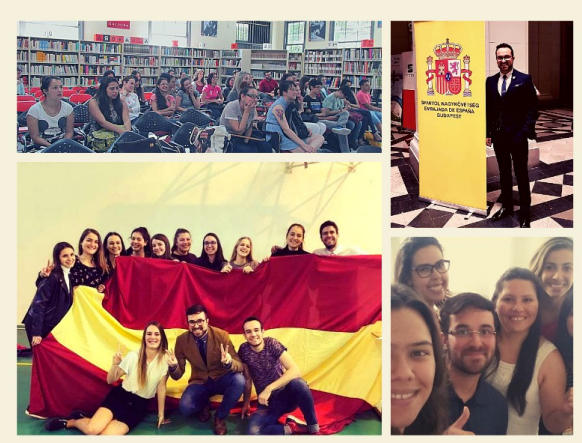

17 OE JUL10 DE 2020- 9H30. MICROSOFT TEAMS 


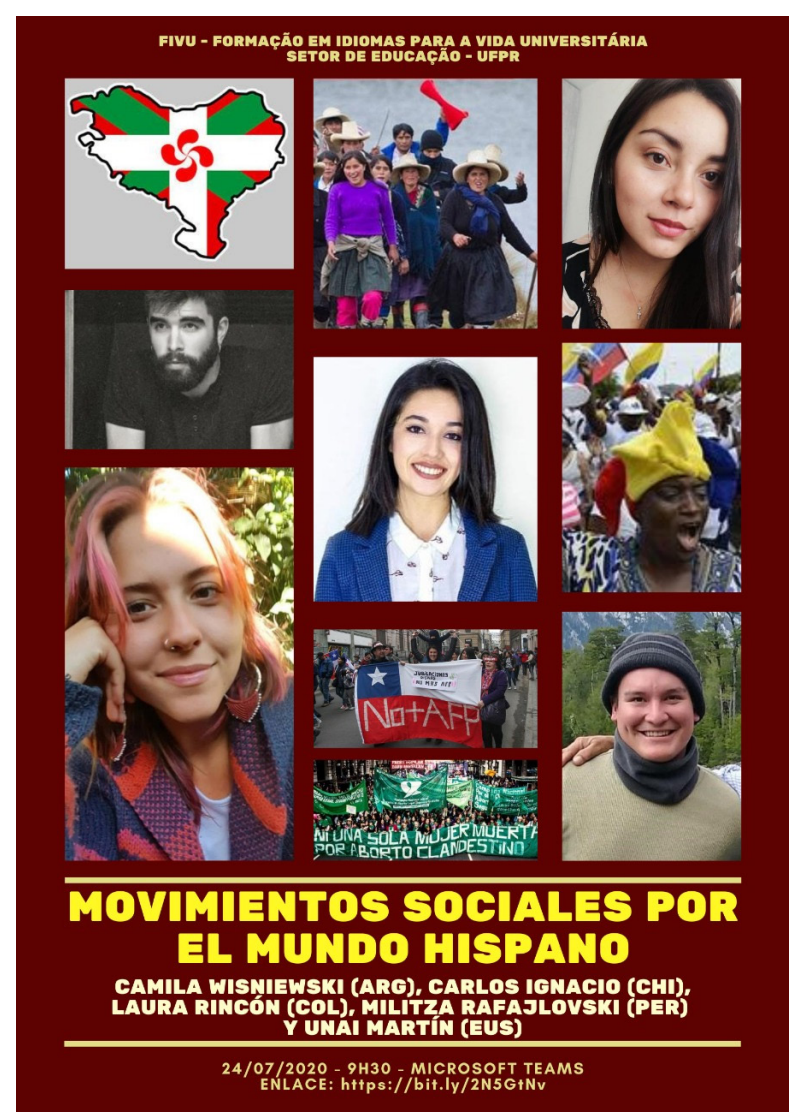

As imagens utilizadas nos cartazes são de acervos pessoais dos envolvidos ou encontradas no Google. Cartazes produzidos para divulgação interna.

Recebido em: 14 ago. 2020.

Aceito em: 07 out. 2020. 
